\title{
THE VALUE OF PARTICIPATION IN URBAN WATERSHED MANAGEMENT
}

\author{
Ryan $\mathrm{R}^{1}$ and Brown R.R ${ }^{1 \& 2}$ \\ ${ }^{1}$ School of Social Science and Policy and ${ }^{2}$ School of Civil and Environmental Engineering. \\ The University of New South Wales, Sydney, NSW, 2052, Australia \\ Paper presented at Watershed 2000-10-23 8-12 July 2000 \\ Vancouver, British Columbia, Canada
}

\section{KEYWORDS}

Stormwater, source control, community education, public participation, policy, community, social action.

\section{INTRODUCTION}

Over the last thirty years the impacts and consequences of poor stormwater quality have been reflected in social concerns and the consequential increase in citizen action groups around the issue of the environment. Environmental degradation such as polluted beaches, inland rivers and coastal zones, contaminated land sites and loss of flora and fauna are broad social concerns needing an integrated community, industry, governmental and institutional response.

All levels of governments from many nations and the United Nations have come together in various forums to discuss management of the environment. Amongst other important issues such as global climate change key agenda issues include how to manage poor water quality to ensure, protection of the aquatic environment, and a sustainable supply of potable water for the future. These processes, based on sharing environmental values, expertise and knowledge, have resulted in the development of ecological sustainable management strategies that can be incorporated into bureaucratic policy processes.

The Australian approach to stormwater quality management has vigorously incorporated the principles of ecological sustainable development (ESD) at national, state and local policy levels. The policy process is different from the former municipal drainage masterplan, demanding stormwater planning on a watershed scale which conflicts with the existing jurisdictions of councils. Not only has the scale of management differed, the overall focus for intervention has broadened and moved further up the pipe. Inline with the philosophy of ESD, source control solutions based on social, ecological and economic values (expressed by stakeholders and the community), which reflect the preventative paradigm, are a key activity area. Central to this recently overhauled policy terrain is engendering community ownership and a shared responsibility for the effects of poor stormwater quality (EPA, 1997 \& Sharpin et al, 1999).

Community education has recently been a common strategy employed as a non-structural source control technique in NSW, and our research demonstrates that it is the favored, all-be-it some what ill-conceived technique. The actual success of these campaigns rely on the referred impacts of litter and some preventative health campaigns, with very little existing reliable empirical evidence of the success of community education in watershed management to support these endeavors. The history of community education in watershed management and urban planning in Australia can be generally characterized as patchy with very limited real outcomes for successful community engagement in the issues. Various attempts by government agencies from the late 
1960's have resulted in considerable disillusionment at both the levels of the community and the implementing officials.

It will be discussed in the Sections to follow how source control solutions have been conceptualized within a limited framework. This claim is based on both policy content analysis and implementation research of stormwater management planning. Source controls have been located primarily in the education response domain that is narrow in its focus and does not necessarily enable behavior change. Contemporary Australian policy and practice is reviewed in light of this introduction to source control. We conclude with the proposal that community education needs to be conceived as a technique for public participation in watershed management to enhance success.

\section{Where is source control located in watershed management?}

The stormwater treatment-train continuum (UDFCD, 1992 also cited in WEF 1998, 65) is a common framework for conceptualizing the range of watershed management options and is depicted in Figure 1 below. This concept locates the traditionally dominant response (mainly structural) and opens up the role and relationship for responses that concern community and council processes. Therefore this approach assists in identifying non-structural source controls, structural source controls and end-of-pipe techniques for developing a management strategy. Summaries of the treatment-train options include: -

- Non-structural source controls - interested in minimising society-generated contaminants by influencing human behaviours and expectations about their environment. This may be achieved through education, changing maintenance activities, applying appropriate planning controls, enforcing and developing regulatory systems and formulating and implementing incentive mechanisms to reduce contaminants. Also these controls are interested in managing the natural evolution of watersheds and urban landscaping which result in contaminants that enter stormwater systems. Brown (1999a) offers a description of these types of responses;

- Structural source controls - techniques that aim to reduce the quantity and improve the quality of stormwater at or near its source by retrofitting existing infrastructure or natural physical resources such as using infiltration basins or rainwater tanks; and

- End-of-pipe controls - concerned with the separation of contaminants from stormwater by using physical, chemical and biological means before entering receiving waterways. These techniques include mechanisms such as artificial wetlands and gross pollutant traps. 


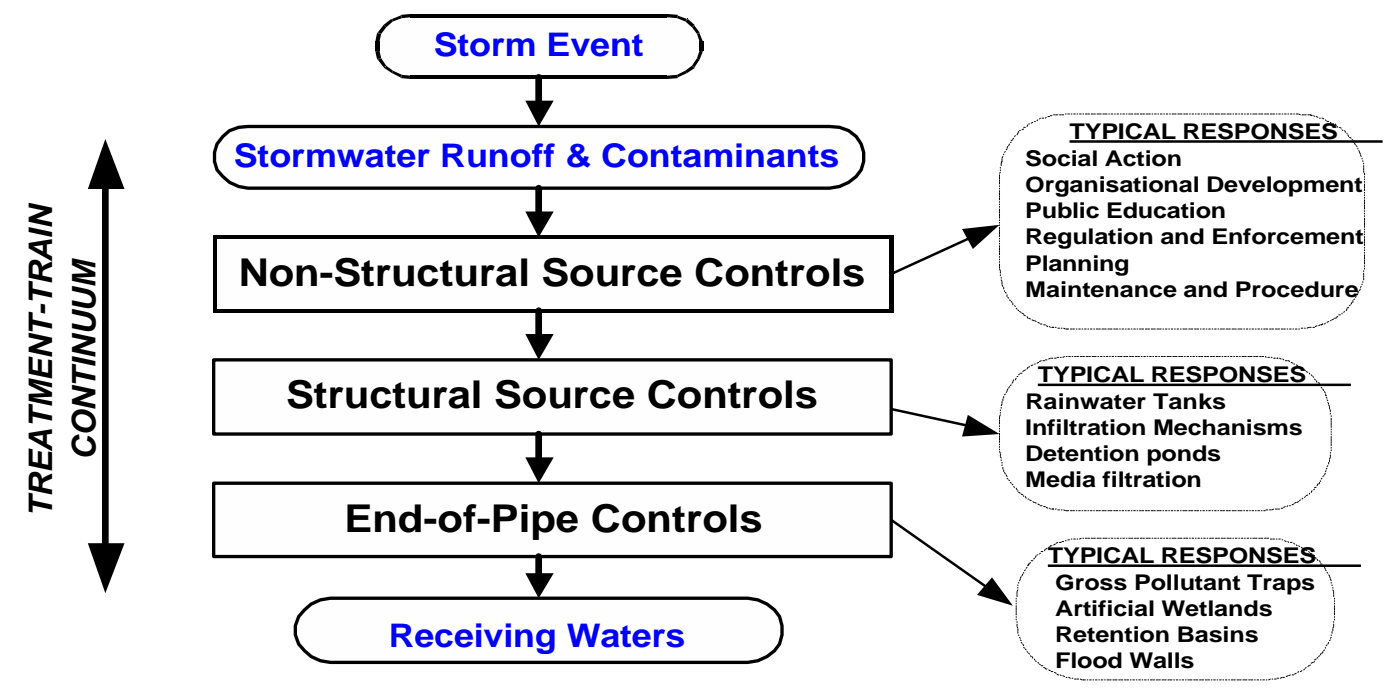

Figure 1

Treatment Train Strategy for the Watershed Management Planning (UDFCD, 1992 and reproduced in WEF 1998 and Brown \& Ball 1999)

\section{Contemporary Australian practice: source controls}

The launch of both the national (NWQMS, 1996) and state (NSWEPA, 1997) policy guidelines, reflecting ESD and the treatment train concept, for urban watershed management has had immediate consequences. In 1997, The NSW government has created a $\$ 60 \mathrm{M}$ program over three years to encourage local councils to plan for stormwater management. The plans being prepared are to focus on controlling stormwater pollution at source using a variety of responses other than the end-of-pipe approaches wherever they are cost effective.

This new planning process is particularly noteworthy because source control activities based on community values and preventative action have been explicitly prioritized as detailed in the policy documents. Not only are ESD principles reflected in the policy but also the emerging preventative paradigm by moving the locus of intervention further along the continuum toward non-structural source controls.

This source control philosophy of changing behavior and ESD has implications for the treatment-train management strategy for urban stormwater. It extends and integrates the treatment continuum from physical intervention to social action. It also moves the site for action closer to the source. These types of actions are really about the communities' relations with the environment and hence translate to social action responses. Figure 2 is a conceptual illustration of contemporary stormwater management, which builds on the existing treatment train continuum and broadens the management strategy. 


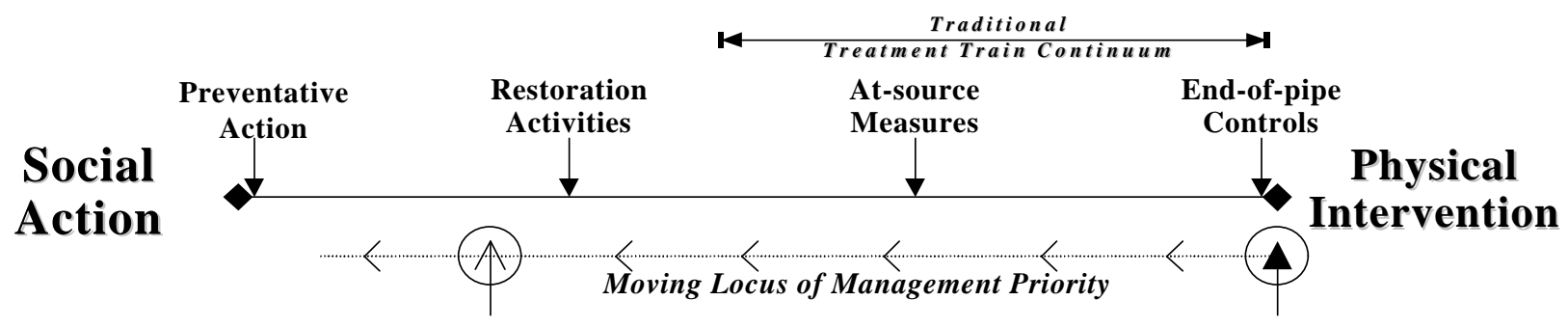

Figure 2 Contemporary treatment continuum for urban stormwater

\section{CRITIQUING CONTEMPORARY AUSTRALIAN PRACTICE: IMPLEMENTATION RESEARCH}

Collaboratively, the School of Social Science and Policy and the School Civil and Environmental Engineering (University of New South Wales) are conducting an on-going transdisciplinary research program into the preparation and implementation of stormwater management plans. Since July 1998 it has been of particular interest how the overall planning process incorporates and supports the initiatives of ESD and its associated emphasis on preventative action. Also of central interest are how and why source control solutions have been conceptualised in the policy process and what solutions have been devised in practice.

Of particular concern to this discussion (with consideration to Figure 2 above) is the implementation research undertaken to identify the types and range of solutions that resulted from this planning process. Each of the plans identified at least one activity in three of the four areas of: - technology, catchment maintenance, regulation/enforcement and education. However the range of proposed costs for these types of activities varied greatly. Physical technologies overall far outweighed the costs of the other proposed solutions and education campaigns were identified as the least cost options. Overall the solution outcomes were a mix of the following: -

- Technologies: a range of specific technologies concerned with external control of the environment. These types of solutions included - road and gross pollutant traps, detention tanks, structural flow controls, artificial wetlands, structural environment protection barriers and detention and sediment ponds;

- Catchment maintenance: reviewing and refining existing catchment maintenance and monitoring procedures which local government are responsible for. These types of solutions included a range of proposed planning and review studies for the future including economic, management and population health. They also included monitoring of street sweeping, water quality, sewage overflows, natural wetlands and aquatic habitat; and conditions of various infrastructures, disposal facilities and garbage disposal methods;

- Regulation/Enforcement: developing and/or refining existing regulation and enforcement policies such as fines for illegal and polluting practices. These types of solutions included conducting various industry audits, introducing penalty systems for polluting practices and law enforcement and licensing practices; and

- Education: a wide range of non-specific community and business education campaigns on activities such as car washing, business practices, waste collection and recycling, efficient water usage, drainage stenciling and unspecified programmes. 
Overall the plan solutions were mostly weighted towards technologies and catchment maintenance activities. If we refer back to Figure 2 above these solutions are really weighted between at source measures and end-of-pipe controls.

This research also involved interviewing implementing officers. These officers were asked how they incorporated source controls that achieve behavior change and engender community ownership into the planning process ${ }^{1}$. The overwhelming response to this line of questioning is that through community education these behavior changes will be realized or if not it is just too difficult for the officers to undertake successfully.

In summary the locus of responsibility remained a technical response rather than one concerned with community activities and practices, despite the guidelines for the development of plans by the funders. Text Box A. is a goal statement description of application of these responses.

It is argued in this paper that even though education processes are important they are limited in their capacity to produce the sorts of outcomes that will achieve social action as indicated in Figure 2. Discussed later in the paper are the reasons why current practice is considered limited and how these impediments can be reconceptualised to realise genuine social action. This reconceptualisation needs to include participatory strategies, and a proposal for a project that seeks to trial this approach is described.

\section{Watershed Planning in NSW - general findings}

To put these findings in a broader context to the overall research programme which has investigated various stages of the planning process from conception through to the completion of forty watershed plans. The major findings of this policy and implementation research are presented in Brown (1999), Brown et al (1999a, b \& c, 2000) and Ryan and Brown (2000). A summary of the major findings of the research includes: -

1. The process worked well for developing first time working relationships between different council stormwater officers' within the watershed, and state government officers';

2. Generally, councils became more aware and educated about the need to manage the effects of poor stormwater quality because of the programme;

3. Overall, councils felt ill equipped and/or uncommitted to the legally imposed planning programme. A majority of councils employed consultants (mainly engineering) to assist in the plan preparation process; (which has negative implications for the organization change and the subsequent organisational responsiveness of the councils)

4. Planning essentially resulted in an undemocratic process because local communities were 'artificially' involved through token efforts at community participation;

5. Local implementers lacked expertise when working with the non-technical community and put little value on potential input from these communities;

\footnotetext{
${ }^{1}$ This research is yet to be published, but related survey information from these officers' can be found in Brown (1999b, c) and Ryan and Brown (2000).
} 
6. Local implementers perceived the watershed community to be apathetic and not having sufficient expertise to be properly involved in the process;

7. Technical experts (mostly engineers and environmental scientists) and technical knowledge (scientific) dominated the policy process. Watershed values expressed in the plan documents were filtered through a technical worldview and were receptive to quantification; and

8. Proposed planning solutions predominately consisted of physical interventions concerned with external control of the environment (end-of-pipe), as opposed to societal and organisational innovations concerned with preventative and protective source actions.

List of the Six Commonly Identified Source Control Responses

1. Regulatory response

Regulatory responses are usually top-of-mind, such as development controls and fining of illegal waste dumpers or litterers. These types of responses may also include economic incentives where charges or rebates are offered to encourage a certain type of behaviour.

2. Planning response

Planning responses involve managing stormwater by design. Typical examples of planning responses would be maintenance of buffer areas to preserve riparian vegetation and the stability of urban waterways. Planning approaches may result in water sensitive urban design in greenfield developments or retrofitting these principles in existing urban areas. These responses can also include the development of planning controls that minimise the impacts of new developments.

3. Education response

Education responses seek to change the behaviour of sectors of the community who impact on stormwater through their day to day activities. Educational programs for stormwater should focus on particular target audience and may include industrial programs for small business or community education programs encouraging Mum's and Dad's to sweep up and keep gutters clean to reduce the impacts on stormwater.

4. Procedural response

The way in which we conduct our activities at work can impact on stormwater quality. Processes like chemicals handling, housekeeping of depots and workplaces and activities like street cleaning and road maintenance can be improved. A procedural response is likely to involve an environmental review of activities and the development of standard operating procedures, which can be monitored and updated, as new technologies become available.

5. Onsite response

An onsite response uses structural approaches to stormwater, but located as close to the source of the pollution as possible. These could include incorporating grass swales or filter strips within an urban development or installation of rainwater tanks or infiltration devices to reduce stormwater runoff.

6. The offset response

In some instances, it is more cost-effective to target pollution in another part of the catchment than reducing the stormwater impact of a new or existing development at source. The offset response could look for opportunities to rehabilitate or remove other pollution sources from a catchment to allow a more modern, high quality development to proceed without expensive end of pipe controls. The potential benefit for the catchment is that there will be no net increase in pollution loads. There may even be an enhancement of water quality or habitats in the catchment.

Text Box A: A Contemporary Range of Source Control Responses (Brown 1999) 


\section{How is community education conceptualized and implemented?}

The education responses as detailed in the plan documents included the following proposed range of campaigns: non-specific community and business education campaigns on activities such as; car washing, business practices, waste collection and recycling, efficient water usage, drainage stenciling and unspecified programmes. These programme were identified by title only and cost allocated to them. No details were reported about how or when they were to occur. Generally the campaigns landed higher up the priority list because they were a lower cost compared to the technology solutions. Campaign costs varied from a minimum of $\$ 3,000$ to $\$ 500,000$ for activities such as drain stenciling. The average cost for a campaign comes out to be about $\$ 50,000$.

There are many definitions of community education. "This is generally understood as learning in the community, or an informal setting, for example, on-the-job training and professional development activities, short courses in evening colleges, point-of sale promotions, advertising, information programs and community events. A key issue is the extent to which programs involve the community in "thinking globally and acting locally.",'(EPA, NSW 1996, 8).

Community education has historically focused on attitudinal change as a result of information giving, with the assumption that behavioral change would be a consequence. The three disciplinary origins of community education include adult education, community development and social action strategies. Practices have generally been dominated by education and information giving with little attention to factors that may lead to social action strategies. A comprehensive review of the literature finds very little evidence of the success of traditional community education activities (Uneputty, et.al. 1998, Robinson, 1999, Rundle, 1995, McIntyre, 1995, Nancarrow, 1997, Medway, 1999, Young and Collier, 1999). There have been questions raised about the issues of motivation to change and how that may impact on outcomes. Community education has really aimed to be about social change - but is generally undertheorized as to how that will occur.

The best examples of practice models (EPA, NSW) draw together causal linkages. These include identifying: -

- social values and community norms,

- socio-demographic variables

- structural and institutional factors

- recent events

- existing levels of individual awareness

- behavioral commitment and intention

- observable behavior

- the current state of the environment.

(EPA, NSW, 16)

The principles of community education usually include being; - lifelong, holistic, locally relevant, emphasizing values, future oriented, action oriented, learner centered, problem solving, systematic, experiential, flexible and adaptable (EPA, NSW 1996, 20). 


\section{Innovative ways to improve water quality in Waverley Local Government Area, NSW: Evaluating the value of community education as a source control strategy.}

In our project currently underway we are evaluating a community education strategy for improving stormwater quality in a local government area in NSW. The Stormwater Trust, EPA NSW, under an Environment Protection Authority Grant, funds the project. This is an innovative trans-disciplinary project, exploring the impact of behaviour change by community members to reduce the negative impacts of stormwater pollution on the waterways of four catchments (subwatersheds) in Waverley Local Government Area (WLGA). This project seeks to improve the quality of water at the local beaches and the Centennial Park ponds. The project has employed both social research and environmental engineering expertise to develop and guide a range of community education strategies for positively impacting on behaviours (by members of the community, land-use patterns and activities by workers at Waverley Council) to reduce water pollution.

This project has investigated the effectiveness of non-structural techniques (ie. community behaviour and organisational arrangements at Waverley Council) to control stormwater pollution in urban areas. The design, implementation and evaluation of the project has drawn together the University of NSW (UNSW) Schools of Civil and Environmental Engineering, and Social Science and Policy with Waverley Council. The project has taken place in four (4) stormwater catchments in the Waverley Council area within the suburbs of Charing Cross, Bronte, Tamarama and Vaucluse. It has included the installation of three (3) new stormwater quality improvement devices, and the extensive physical monitoring and social research to assess attitudinal and behavioural change.

There are four (4) objectives:

1. To involve the community in stormwater pollution reduction strategies and evaluate the effectiveness of strategies on specific groups, land uses and activities.

2. Provide quantitative information on the effectiveness of community education programs in reducing stormwater pollution at source, in both residential and commercial areas.

3. Develop innovative community education strategies that could be adopted by other councils.

4. Assess the cost/benefit of installing stormwater pollution control devices in small residential catchments.

The community education element of the program aims to test, for the first time, the impacts and benefits of community education programs aimed at reducing stormwater pollutants at source. This will be achieved by: - determining the success of different types of community education campaigns on different groups within the population (such as ethnic groups, gender, age); assessing who are the most responsive target group for community education (such as adults or children); ascertaining the effectiveness of community education programs in residential and commercial areas.

The monitoring will provide the necessary data to assess community attitudes, behaviour and quantify the pollutant loads. The types of monitoring to be used will include: detailed social surveying, observational analysis of actual activities and land-use patterns in the catchments; measurement of pollutants, by chemical analysis of materials from street vacuuming and sampling of gross pollutant traps; and video observations in commercial areas. Surveys have determined baseline values, attitudes and motivation to change, and the post-test survey will determine post intervention if there have been changes in these areas. The physical sampling of 
dry weather pollutants on the road and gutter surfaces and grab samples from pollutants captured in the stormwater quality improvement devices will provide physical monitoring of baseline data of pollutants. Video surveillance in the commercial sector will provide information on daily activities relevant to stormwater pollution. The project is currently at the stage where the pre-test activities have been completed, and the community education campaign is about to commence.

\section{Results from the pre-test data ${ }^{2}$}

The social survey asked respondents about knowledge of, and attitudes to, stormwater contamination; they were also asked to describe their behaviours (which would impact water quality); and about their willingness to be involved in improving stormwater quality, their relative concern for the environment and the importance of water quality. They were also asked about the best ways to transmit information to them to help focus the community education campaign. The results of this survey, along with the physical monitoring are being used to direct the content and the types of community education campaigns.

One interesting finding is that most people are concerned that the visible aspects of pollution (especially litter) but the comparison with the technical data show that organics and sediment (non-visible in community terms) are the worst pollutants in the four watersheds that can be directly impacted by community activities. Our research demonstrates that there is very lowlevel knowledge in the community that organics (such as leaf litter) are harmful to water quality. This highlights that there exists differences in perceptions by the community and the physical data of contaminant sources. Community education approaches determine that it is important, using a learner centred approach to work with this perception as one of the foci for change. This has become the primary focus of the campaign. The behaviours that then become important here are car washing, disposal of garden refuse, hosing of pavements, and the management of construction sites. The current behavioural practices regarding these have been described in the pre-test survey and the post-test measures will test for reduction in sediment and organic loads, changes in knowledge, awareness as well as behavioural changes.

\section{Evaluation of the value of community education}

Despite the emphasis in most understandings of community education on the importance of 'learner centered' approaches, the programs are generally designed by professions and then introduced into the community, by using inadequate information about community perceptions and behaviors. While the project described above has taken the social inquiry dimension of the community education strategy more seriously than is usual and it is hoped will improve the effectiveness of the campaign (the results of which will be available later in 2000), it still lacks the two important ingredients of being devised by the community (a bottom-up approach) and a significant public participation element. We are seeking to further test these ideas in the project that is described below.

The implementation model is generally one that is consultative, but basically devised at 'the top' and delivered by 'experts' from outside the site of the intervention. The classic top-down implementation model is described for community education by the Environment Protection Authority in NSW, which is the premier organization for environmental education, as requiring

\footnotetext{
${ }^{2}$ These results here are highly summarised, and aim to be only illustrative of the type of work undertaken. The data is subject to analysis by catchment, by demographics and household type and there are important differences in these areas. The full details of the results will be available later in 2000 .
} 
the steps - identify the problem, choose a solution and develop a strategy, evaluate the strategy (EPA, NSW, 20). While this process is to identify stakeholders and identify roles and responsibilities, it is consultative at best, rather than participatory. It may be possible to increase community awareness by information giving, but we are unlikely to stimulate social action (as per Figure 2) without moving the locus of activity up toward being more participatory.

Not only is participation broader than education in terms of producing a source control response, the process of appropriate participation is a response outcome in itself.

\section{The importance of public participation in extending the success of community education strategies}

Public participation in stormwater management involves developing a partnered or shared analysis of both the problem and solution. This partnership is enabled through deliberative processes that involve all forms of knowledge and expertise. Deliberation here encourages any worldview to be subject to questioning, argumentation and debate. These debates, as part of the process must occur between all stakeholders. These types of processes enable participants to develop a shared construction and meaning of the issues - even if these are in contradiction (Forester, 1993). This is particularly important in terms of dealing with the conflicting views of 'experts', community members and others in defining and prioritising fields of action in managing the watershed. If litter is considered the main problem by the community, this cannot be ignored (even if it is not a significant cause of contamination) without the risk of loss of community engagement in the process. There needs to be a managed approach which balances issues of importance for the community (often around amenity or visual impacts) as well as the technical concerns which may not immediately resonate with the community. The community as well as the traditional 'experts', i.e. engineers and environmental scientists, can be educated.

Consensus decision-making is based on the notion that all participants have power for arranging the practices in the operation of the planning process, and recognises that these practices themselves will affect the outcomes. Without the engagement by the community, many of the problem causing behaviours will go unchanged. Also, the planning stages and decision outcomes are only valid if they are agreed to in advance by consensus. This action bases the planning process on the ideals of cooperation and collaboration where participants with different worldviews are primarily concerned with educating, influencing and learning from and with their peers. This type of process enables the views of all stakeholders to become relevant to the management process and therefore enabling their participation. Jurgen Habermas's (1984 and 1987) theory of communicative action is an ideal methodology for this type of process. The process should be transparent and accountable to all participants. Without these basic preconditions, open accountable, participative process is not possible.

It is considered that broad participation and consensus are the key vehicles for improving the management of urban stormwater through social action by:

- enhancing the role of the civil society, democracy and citizenship in issues that directly concern the citizens themselves; and enhancing the participant's sense of social or communal responsibility for the sources and effects of contaminated stormwater;

- providing a forum where fundamental technical assumptions can be openly questioned and challenged, improving the collective conceptualisation of the issues;

- offering a process where technical problem ambiguity, indeterminacy and solution uncertainty can be broadly managed, shared and addressed by the community; 
- significantly improving local community support for stormwater management and future implementation activities;

- generating dialogue, definitions and terminology around the concerns of stormwater contamination that are established and agreed upon locally;

- formulating action-based solutions that address the generation of contaminants through critical self-reflection of community practices and expectations, facilitating solutions concerned with individual, organisational, and societal innovations or mobilisation;

- improving and strengthening the relationship between citizens and government by developing the performance potential of governments to meet communities' concerns and tapping the knowledge and social capital of communities for governance concerns; and

- the watershed community setting the desired performance levels for the authority to facilitate rather then the authority imposing upon the community.

\section{Civic Environmentalism}

By using the power of place, civic environmentalism (CE) can be a process for reducing diffuse stormwater contaminants at the source. The aim of $\mathrm{CE}$ is to enable citizens to act responsibly in ways that do not threaten their sense of entitlement. Their civic spirit is free to flourish when their private interests are made more secure (Knopman et.al. et al, 1999). Place-based diffuse stormwater contaminants require civic treatment. It is those civic expectations about the form of their urban environment and the activities that they undertake in this environment that dictate the type, frequency, load and potential toxicity and harm these contaminants cause. As demonstrated by some key landmark projects (Knopman et al, 1999) the facilitation of civic environmentalism is one such approach, which attacks the problem head-on. 'Civic' emphases the particular commitment to engaging citizens. The Civic Environmental web site http://www.dlcppi.org/ppi/enviro/civic describe five successful environmental case studies involving collaborations between citizens, property owners, environmental action groups, and local, state and federal agencies. These case studies describe lessons learnt from these collaborative efforts and the potentials of such approaches for solving difficult and diffuse problems of natural resource issues such as urban stormwater.

The Chesapeake Bay Programme shows, for example, the more that the citizens recognize that 'the enemy is us,' the more that they are inclined to acknowledge their own part in the problem. They pierce the veil of abstraction attached to terms like 'non-point source' and start to think about how they might reduce their own use of lawn chemicals and encourage their neighbors to do the same. Furthermore, they come to see themselves as pollution fighters in much the same vein that the community policing movement has encouraged ordinary citizens to think of themselves as crime fighters. Personal responsibility, civic education, and mutual vigilance replace coercion from afar as the bases for community involvement.

$\mathrm{CE}$ has been described as a "clear departure from the first generation of national environmental policies that have tended to impose top-down and prescriptive solutions to address one problem at a time, independent of the circumstances in a particular place. For yesterday's pollution problems, the first generation policies worked, but the more complex and often diffuse environmental problems of today demand new tools of engagement. Civic environmentalism is a cornerstone of a second generation of environmental stewardship that redefines responsibilities among levels of government, yet roundly rejects national divestiture in environmental matters; thrives on innovative problem-solving in the private and public sectors; and harnesses market forces to drive better environmental performance' (ibid, introduction). 
The common thread of diffuse pollution problems like urban watershed management is the important role of land-use decisions and the interplay of public objectives with private property rights

\section{An example of a proposed Australian project for public participation in watershed management}

This project will facilitate and investigate the effectiveness of a community based participatory process to develop self-implementing and sustainable solutions to manage and improve stormwater quality with in the highly urbanised catchment of Bronte. Bronte residents have identified water pollution as the most important issue affecting their community (Eastern Suburbs Stormwater Management Plan; Water quality Survey for the Waverley Local Government Area (Ryan and Mack, 2000) and Community Indicators Survey for the Waverley Local Government Area (Ryan, 2000)).

Previous consultation with the Bronte community on the selection and location of the installation of a structural stormwater management solution has revealed there to be a very good understanding of stormwater management and a willingness to be more actively involved in constructing community-based solutions to point source and diffuse pollution.

This project will positively reshape the communities' relationship with both their physical environment and each other, by acknowledging and working with their different worldviews, expectations and behaviours that adversely impact the quality of stormwater. The expectations, knowledge and behaviours within the different factions of the Bronte community and Waverley Council, that result from the participatory process, will be progressively investigated and monitored. The project's orientation is action-based and will continuously reflect to the needs and desires of all involved while prioritising the goal of reducing community generated at-source pollution throughout the project. A mix of all advocated representation methodologies including self-selection, random selection, selection by invitation and electoral will be employed.

It is hoped that through initiating a state-of-the-art participatory process, based on the needs and desires of the Bronte community, reflecting the advantages of open government, the following outcomes are achieved:

- The sources of community generated stormwater contaminants are reduced;

- The development of a communal norm for protective and preventative behaviours that protect the health of Bronte's water environment;

- The emergence of various organisational innovations within Waverley Council responding to the issues identified and solutions developed by the participatory process; and

- The dialogue and participatory process becomes self-sustaining and self-governing (by the community) after 12 months.

In particular it is hoped that the deliberative process will offer a real solution to this continuous problem that has been, so far, ineffectually solved. Diffuse urban stormwater contaminants are difficult to adequately conceptualise, manage and measure because they rely on understanding the interactions between place, and social expectations and activities that generate these contaminants. So far, attempts at treatment have been limited to end-of-pipe interventions and top-down community education programmes. These solutions are insufficient for (1) engendering community ownership and responsibility, (2) establishing terminology and dialogue 
that does not restrict citizen involvement, and (3) developing sustainable solutions by the community for the community.

Solutions that stimulate social and governmental innovation are needed for addressing diffuse pollutants. These innovations can only be conceived through recognising that the 'community' is not a coherent entity with a clear identity and a commonality of purpose. The reality is that communities, more often than not are made up of an agglomeration of factions and interest groups often locked in competitive relationships. This project needs to recognise and positively draw on these differences by facilitating shared deliberation over the issues and stimulating the civic role of these factions' and groups'. Local participatory processes have potential for producing these types of outcomes. This project will facilitate such a process concerned with constructing a shared problem and solution rationale using the both the language and broad knowledge domain of Bronte community and Waverley Council.

There are two main components:

1. To implement and facilitate a deliberative processes that addresses stormwater quality that involve all sectors of the community. In particular this will include those that are generally difficult to identify, or normally impeded from participating in civic issues, and/or not readily perceived as effective stakeholders by the stormwater industry. Constructing and motivating preventative action based on solution rationales that have been collectively constructed is the objective of the project.

2. To monitor the internal and external effectiveness of the process through employing continuous social action-based quantitative and qualitative measures and periodic physical quantitative measures.

This project proposes to test the argument put in this paper that social action will be enhanced by improved public participation process, and that this will lead to measurable improvements in water quality.

\section{LIMITATIONS OF CURRENT STORMWATER MANAGEMENT PRACTICE}

As discussed above the scope of the community or social action targeted responses have been limited to a range of non-specific education campaigns in the stormwater management planning process. This type of solution conception indicates the following possible notions: -

- $\quad$ social action and source control activities are not well understood by implementing officers';

- the community is understood to be a single entity with a common purposes and values; and

- social action is not believed to be a viable option and only technologies can solve the problems of poor stormwater quality.

When considering the nature of the contamination cycle that leads to stormwater pollution as depicted in Figure 3, it can be seen that not only is it about behaviors but also community expectations about their form and operation of their environment. So for campaigns that are often devised by a group of 'experts' with different values and understanding of the issues from their target audience, how can these be effective? 


\section{Contaminant cycle}

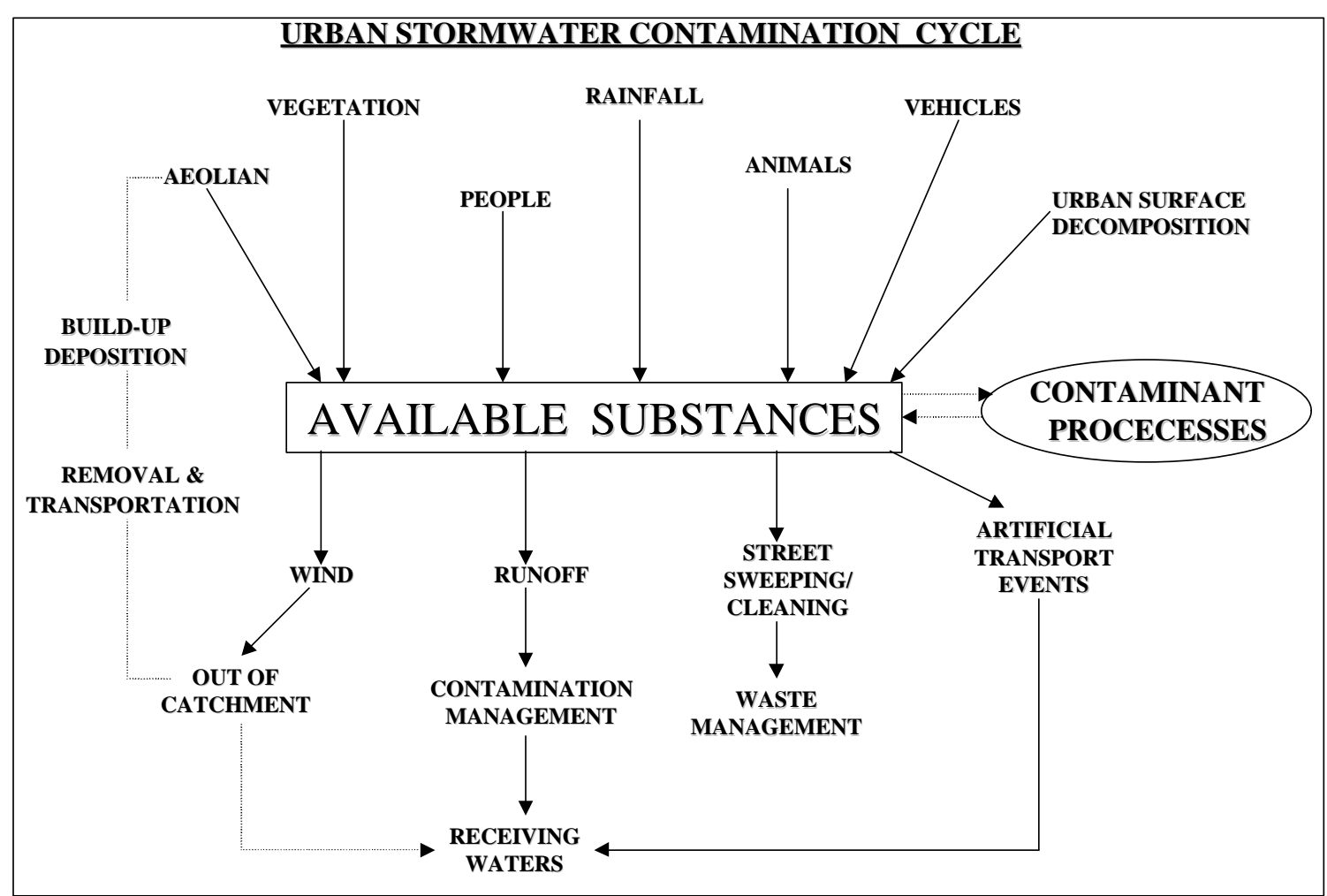

Figure 3 Urban Stormwater Contamination Cycle (devised by Rebekah Brown, James Ball and Peter Davies - UNSW)

The contaminant cycle is rich, complex and in some respects in-determinant. As evidenced by Figure 3 the generation of contaminants not only involve direct activities by industry and communities, but also natural processes such as wind and rain that erode surfaces such as roads, roofs, parks and gardens. Consequently not only do our activities such as driving cars impact the stormwater environment but our expectations of our environments' form (i.e. roads for transport, rose gardens [using migrant species] and changing landforms for aesthetic reasons [which changes natural drainage patterns] ) impact the water quality environment. So our artificial urban drainage systems involving drainage pipes and pits act as catalysts to mix up contaminants and potentially facilitate the development and/or transport of substances that degrade the receiving water environment. Therefore can a predefined education campaign tackling single activities such as car washing be really useful for minimizing the contaminant process? Should we not being trying to tackle the root cause? Or should we be developing indicators that communities can relate a range of activities to so that there is a more integrated or at least broader ranging responses. Education appears to be working from the outside to the inside when considering Figure 2. It is top-down or about external control at a point source of a process. Whereas if participation is conceptualized as in Figure 2, it is working from the inside out. We are advocating a bottom-up approach, which is concerned with spreading control and ownership as widely as possible throughout the urban watershed community to enable the most effective treatment outcomes. 


\section{CONCLUSION}

The conclusion is that there needs to be a multifaceted approach that includes government behaviours, industry behaviours, new governance structures, continuing political pressure from communities and greater electoral responsiveness. It is argued in this paper that community education is limited in its impacts if deliberative participation strategies are not also deployed in stormwater management. The current use of community education in NSW is both limited and often inhibited by officer lack of commitment, poorly conceptualised role of community and inflexible institutional practices. Even in more highly developed projects as described here, with better use of social research to target community education interventions, the outcomes are expected to be inadequate as the process still remains top-down, with limited community engagement, which will constrain the social action outcomes. Without improved participatory strategies, the commitment to values, behavioural and resource changes which are required for improved water quality will continue to be jeopardised.

\section{ACKNOWLEDGEMENTS}

We would like to acknowledge the research team, as these ideas are the result of collective work by James Ball, Anita Mack and Peter Davies. The funders of this project, EPA NSW, are the most supportive and innovative we have ever worked with. Their excellent work in community education for source control is the primary stimulus for us, and we would particularly like to thank Phil Smith and Geoff Young for their ideas, support, and encouragement.

\section{REFERENCES}

Banfield, EC. (1959) Ends and Means in Planning. International Social Science Journal 11:36168.

Barrett S and Fudge C, 1981. Policy \& Action: Essays on the Implementation of Public Policy. Methuen.

Berstein RJ, 1983. Beyond Objectivism and Relativism: Science, Hermeneutics and Praxis. Basil Blackwell.

Bohman J, 1996. Public Deliberation: Pluralism, Complexity, and Democracy. MIT Press, Massachutsetts

Brown RR, (1999), Stormwater Source Control: Facing the Challenges. Comprehensive Stormwater \& Aquatic Ecosystem Management Conference, First South Pacific Conference. February 1999. Volume 2 pg 67-74 Auckland, New Zealand.

Brown RR, Ball JE, (1999a), A review of stormwater management planning as implemented in New South Wales. 8th International Conference on Urban Storm Drainage. September 1999 Sydney, Australia.

Brown RR, Ryan R, Ball JE, (1999b), Catchment-based stormwater management in Australia: Citizen Participation in policy - What can be achieved? International Conference on Participatory Processes in Water Management. July 1999 Budapest, Hungary. 
Brown R.R, Ryan R, Ball J.E (1999c), Community consultation and participation processes for Local Government stormwater management in Australia. International Conference on Public Participation and Innovations in Community Governance. June 1999 Luton, England.

Brown R.R, Ryan R and Ball JE, (2000). A Participative Planning Methodology: Stormwater Quality Planning at the Watershed. Presented at Watershed Management and Operations Management 2000 conference, June 21-23, Colorado State University. Fort Collins, Colorado, USA.

De Witt, J 1994. Civic Environmentalism: Alternatives to Regulation in States and Communities. Congressional Quarterly Press, Washington D.C.

EPA, 1997. Managing Urban Stormwater: Council Handbook. Publication of the Environment Protection Authority, New South Wales. Sydney, Australia.

EPA, 1996. A new approach to ENVIRONMENTAL EDUCATION in NSW, A NSW Government Green Paper, . Publication of the Environment Protection Authority, New South Wales. Sydney, Australia.

Fischer F, 1990. Technocracy and the Politics of Expertise. Sage Publications, Newbury Park.

Forester J, 1993. Critical Theory, Public Policy and Planning Practice. State University of New York Press.

Habermas J, 1984, 1987. The Theory of Communicative Action, volumes I and II. Beacon Press, Boston.

Hill M, 1993. The Policy Process: A Reader. Harvester Wheatsheaf, London.

Knopman, D, Susman, M and Landy, M. 1999. Civic Environmentalism: Tackling Tough LandUse Problems with Innovative Governance, Environment, Dec V41, 10-24.

Medway, B. 1999. Effectiveness of community education programs in reducing stormwater pollution, unpublished, Civil and Environmental Engineering, UNSW

McIntyre, J. 1995. Community and Corporatism: a critique of the concept of community adult education, Australian Journal of Adult and Community Education, Vol. 35, no. 3. November, 178-184.

Nancarrow B. et.al. 1997. Stormwater Management in Australia: Community Perceptions, Attitudes and Knowledge, CSIRO and Urban Research Association.

NWQMS, 1994. National Water Quality Management Strategy: Water Quality ManagementAn outline of the Policies. Australian and New Zealand Environment and Conservation Council. Publication can be obtained from Australian Water and Wastewater Association, Sydney, Australia.

Robinson, L A. 1999. 7-step social marketing model, http://media.socialchange.net.au/scm/strategy/ 
Rundle, J. 1995. The Community Education Formula, Community Quarterly, No. 33, 12-17.

Ryan R and Brown R.R, (2000 FORTHCOMING). Value of Public Participation: Policy for Stormwater Quality for the Watershed. Presented at Watershed Management and Operations Management 2000 conference, June 21-23, Colorado State University. Fort Collins, Colorado, USA.

Ryan, R. 2000. Community Indicators Survey for the Waverley Local Government Area, UNSW Social Science and Policy, Community Indicators and Local Democracy Project, Funded by the Australian Research Council, DRAFT REPORT.

Ryan, R and Mack, A. 2000. Water Quality Survey for the Waverley Local Government Area, UNSW Social Science and Policy, DRAFT REPORT.

Sharpin M, Barter S and Csanki S, 1999. Stormwater Management Planning in New South Wales, Australia. Proceedings of 8th International Conference on Urban Storm Drainage, Vol 4, p 2006-2014. Sydney, Australia

Uneputty, P, Evans, S and Suyoso, E. 1998. The effectiveness of a community education programme in reducing litter pollution on shores of Ambon Bay, Journal of Biological Education, 32 (2), 143-147.

Urban Drainage and Flood Control District (1992) Urban Storm Drainage Criteria Manual. Volume 3 - Best Management Practices, Stormwater Quality. Denver.

Young, G and Collier, G. 1999. Research-based stormwater education at the NSW Environment Protection Authority, Community Education Section, NSW EPA, PO Box 1193, Chatswood, NSW, 2057 (unpublished) 